\title{
Dual control connections in frames for earthquake resistance
}

\author{
M. C. Phocas ${ }^{1} \&$ T. L. Sophocleous ${ }^{2}$ \\ ${ }^{1}$ Department of Architecture, University of Cyprus, Cyprus \\ ${ }^{2}$ Department of Architecture, University of Nicosia, Cyprus
}

\begin{abstract}
The behaviour optimization of structures under severe dynamic actions, such as earthquakes, is being increasingly aimed at the control of the stiffness and damping properties of structures. The present paper examines an alternative control mechanism for achieving dynamic structural adaptability. To achieve a larger degree of freedom in the members' control design, a novel dual connection of the primary members of the frame is proposed, which can initially "filtrate" the moment transmission at the joints. The connection consists of elastomeric material fixed at the primary joint areas and the lower column areas of three frames. The elastomeric shear connections are activated from the beginning of the horizontal excitations of the frame. Consequently, the stiffness of the primary system is no longer restricted to the geometric relations of the connected members. The elastic connection enables, primarily, a displacement increase of the structures and a slight increase of their energy dissipation performance. Based on three representative international strong earthquake motions of differing frequency contents, respective numerical nonlinear analyses of a SDOF system exemplify the earthquake performance of the controlled frames with elastic connections. In perspective, the stiffness control concept may enable further objectives in the design to be achieved for a stepwise adaptation by the primary system to the external acting forces through an increase of its damping properties.

Keywords: earthquake resistance, frame structures, passive control, elastomeric connections.
\end{abstract}




\section{Introduction}

Member structures such as trusses, frames and braced frames are primarily applied in multi-storey buildings, such as horizontal load bearing systems with regard to site-specific wind or earthquake loads. Principally, the systems are differentiated in their elastic stiffness and damping properties, and their displacement behaviour in the plastic response region [1].

Frames primarily transform the horizontal acting loads into shear forces and respective bending moments in the members, inducing relative large joint displacements. The contribution of the axial forces is relatively small compared to the overall systems displacements by conventional buildings [2]. On the other side, the transmission of the horizontal forces in trusses and braced frames is primarily based on the development of tension and compression forces in all members; in these systems the prevention of joint displacements by the diagonals yields to a significant increase of the stiffness of the structure [2].

The damping capability of the structures in the elastic and plastic range increases with increasing deformability. The displacements of multi-storey buildings designed only for wind loads are kept under acceptable limits only through stiff bracings, whereas lack on damping is compensated through special measures [3]. On the other side, the design of buildings in earthquake prone areas takes into consideration two loading cases: wind and code reference earthquakes as ordinary excitations and 'strong earthquakes' as extraordinary excitation [4]. In the first case, stiffness and damping is required; in the second case, additional deformability of the system in the plastic range. Neither moment resisting frames, nor trusses or braced frames satisfy efficiently both requirements at the same time [5].

Moment resisting frames possess large structural reserves for the transmission of strong earthquake excitations. Through development of plastic hinges, the structures are capable to dissipate large amounts of energy. From a kinetics point of view, plastic hinges mean the release of inner structural connections, providing respective reduction of the stiffness, and dissipation of the kinetic energy through plastic hysteresis [1]. This behaviour can be interpreted as a selfadaptation procedure. Throughout this process the structure strives for adapting its behaviour according to the characteristics of the excitation. Along these lines technologies have been developed in the last 30 years that enable a controlled intervention in the dynamic behaviour of structures under wind and earthquake loads $[6,7]$.

Considering the equation of motion of a SDOF system with mass $\mathrm{m}$, reaction force $F_{R(t)}$ and damping force $F_{D(t)}$ under the action of a timely variant load $P(t)$,

$$
m \ddot{x}(\mathrm{t})+\mathrm{F}_{\mathrm{R}(\mathrm{t})}+\mathrm{F}_{\mathrm{D}(\mathrm{t})}=\mathrm{P}(\mathrm{t})
$$

control of the dynamic systems response is possible, either through intervention on the left side of eqn (1), on the reaction force $F_{R(t)}$ and the damping force $F_{D(t)}$, i.e. control of the elastic and damping properties of the system (passive control), or the generation of a counteraction $\mathrm{Q}(\mathrm{t})$ that opposes the resulting displacements of the system (active control). Both, passive and active controlled structures 
comprise under the term 'adaptive structures' respectively independent typologies of structures. Since the technology of passive control is considered to be more reliable and easily implementable, it gained increasing significance over the past years in the safety of buildings against strong earthquakes [8].

In the following sections some aspects of passive structural displacement control of steel frames exposed to strong earthquakes are considered with the aim to propose construction measures for damage limitation of the primary members. Subsequently calculation aspects in the design are explained and three different frame systems are investigated in their dynamic response under three international earthquake motions with differing frequency characteristics. For the investigation, a moment resisting frame is selected as reference SDOF system. Based on the proposed control concept related aspects are discussed in achieving an improved structural adaptability under strong earthquake excitations.

\section{Passive structural control}

An important aspect in the development of dynamic adaptive structures constitutes the control of the structural deformability, i.e. the establishment of a global and local deformation configuration that the structure should obtain under a respective earthquake excitation. As long as the displacements of the structure remain within the elastic range, the reaction force $F_{R(t)}$ in eqn (1) is an elastic force, $\mathrm{F}_{\mathrm{R}(\mathrm{t})}=\mathrm{F}_{\mathrm{el}}=\mathrm{kx}(\mathrm{t})$, linearly dependent on the elastic displacement $\mathrm{x}(\mathrm{t})$ of the structure. The stiffness $\mathrm{k}$ is significant for the elastic deformability of the structure and basically depends on the systems geometric relations, the stiffness of the individual members and the type of supports of the system. An estimation of the structures damping $\mathrm{F}_{\mathrm{D}(\mathrm{t})}$ is based on the Kelvin viscoelastic model assuming a velocity dependent damping force, $F_{D(t)}=F_{d}=c \dot{x}(t)$, whereas energy dissipation takes place through elastic hysteresis.

Strong dynamic excitations lead to plastic deformations of the sections, whereas the frame transforms to a yield-hinge mechanism with new deformation configuration. Its behaviour exhibits strong nonlinearities. The reaction force $\mathrm{F}_{\mathrm{R}(\mathrm{t})}$ and the damping force $\mathrm{F}_{\mathrm{D}(\mathrm{t})}$ are represented by nonlinear relations. The nonlinear behaviour of steel frames is usually described through a simplified ideal elastoplastic model, whereas the largest part of the kinetic energy is dissipated through plastic hysteresis [4].

The control task concentrates on the prevention of structural damages through permanent deformations. Therefore a deformation configuration is selected that ensures dissipation of the main portion of kinetic energy in the elastic range. For this reason it is important to introduce ways that enable control of the system stiffness, avoiding at the same time modification of the structural parameters as to the static requirements of the system, and introduce damping mechanisms to the primary structure that ensure a controlled dissipation of the kinetic energy [9]. 


\subsection{Elastic connections}

The requirements on the system stiffness described in the previous section are not self-evident, even for conventional structural systems, since the dimensions of the members are not derived from the design of the structure for conventional vertical and horizontal loads. Under preservation of the systems geometric relations, modification of the stiffness of the system is possible through introduction of 'connection points' in members of the structure. Any additional local deformations, as for example tensioning that may take place, are controlled by mechanical means.

A possible solution is the application of elastic connections, basically consisting of an elastomeric layer built between the beam and the columns, as well as within the columns at the supports. The transmission of shear forces takes place through consoles or centrally placed steel plates (fig. 1). Distance holders and tension connections between the plates prescribe the elastomeric layer rotational angle.
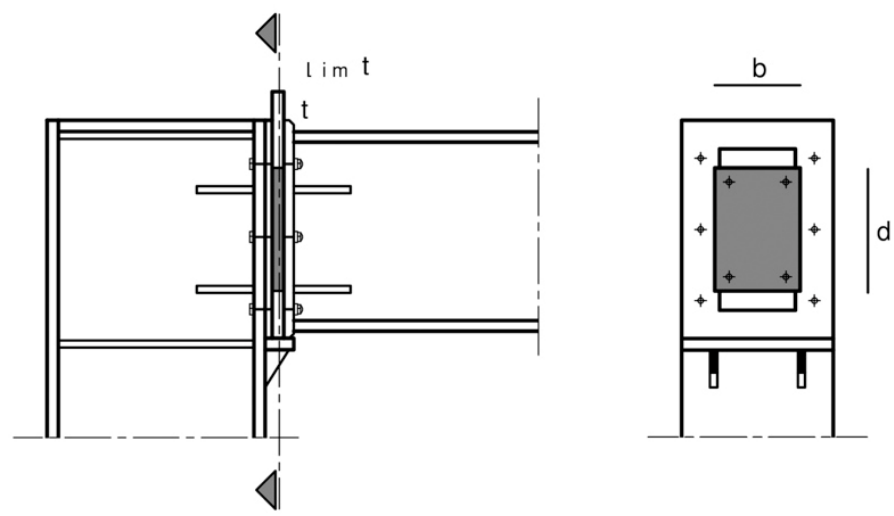

Figure 1: Construction detail of an elastic beam-column connection.

\subsubsection{Elastomeric layer rotational angle}

For a rectangular elastomeric layer with width $b$, height $d$ and thickness the following relation applies between the rotational angle $\varphi_{\mathrm{t}}$ and the resulting elastic moment M [10]:

$$
\varphi_{\mathrm{t}}=\frac{\mathrm{nt}^{3}}{\mathrm{~d}^{5} \mathrm{bG}} \mathrm{M}
$$

The first derivative of the rotational angle $\varphi_{t}$ may lead to an equivalent definition of the notional rotational stiffness of the elastomeric layer in form $\mathrm{K}_{\mathrm{t}} \Rightarrow \mathrm{E}_{\mathrm{t}} \mathrm{I}_{\mathrm{t}}$, as follows:

$$
\varphi_{t}^{\prime}=\frac{1}{\rho}=\frac{M}{E_{t} I_{t}}=\frac{3 n t^{2}}{d^{5} b G} M=\frac{M}{\left(\frac{d^{5} b G}{3 n t^{2}}\right)}
$$




$$
\mathrm{K}_{\mathrm{t}}=\frac{\mathrm{d}^{5} \mathrm{bG}}{3 n \mathrm{t}^{2}}
$$

For the relation $\mathrm{b} / \mathrm{d}=1$, the parameter $\mathrm{n}$ becomes 85.70 [10]. The shear modulus $\mathrm{G}$ is primarily a function of the elastomeric hardness measured in shore units. For shore hardnesses of 40,60 and 80, the shear modulus is 45, 100 and $200 \mathrm{~N} / \mathrm{mm}^{2}$ respectively [10].

\subsubsection{System stiffness}

For determination of the bending stiffness of frames with elastic connections, the horizontal displacement $\mathrm{x}$ of the system is initially calculated. By neglecting the influence of the shear and axial forces, the following equation applies:

$$
x=\int_{0} \frac{\bar{M} M_{x}}{E_{b}} d x+\sum \int_{0} \frac{\bar{M} M_{x}}{E_{t} I_{t}} d x+\sum \int_{0}^{b} \frac{\bar{M} M_{x}}{E I_{c}} d x
$$

In eqn (5) $M_{x}$ is the bending moment induced by a force $P$ that acts in direction of the system displacement $\mathrm{x}$ at the height of the beam, and $\overline{\mathrm{M}}$, the bending moment due to the virtual support action $\mathrm{P}=\mathrm{I}$.

With $\mathrm{x}=1 \mathrm{~cm}$ in eqn (5), the stiffness $\mathrm{K}_{\mathrm{H}}=\mathrm{P} \mathrm{kN} / \mathrm{cm}$ is provided. For a hinge supported frame of height $\mathrm{h}$ and span $\mathrm{l}$, with elastic beam connections, the system stiffness is given by the following equation:

$$
\begin{gathered}
\mathrm{K}_{\mathrm{H}}=\frac{12 \mathrm{EI}_{\mathrm{c}}}{\mathrm{h}^{3}\left(\frac{2 \mathrm{k}+1}{\mathrm{k}}+\beta\right)} \\
\beta=\frac{\mathrm{t}}{\mathrm{h}} \frac{\mathrm{EI}}{\mathrm{K}_{\mathrm{t}}} \\
\mathrm{k}=\frac{\mathrm{I}_{\mathrm{b}}}{\mathrm{I}_{\mathrm{c}}} \frac{\mathrm{h}}{1}
\end{gathered}
$$

For a frame with moment resisting supports and elastic beam and columns connections the system stiffness is given by the following equation:

$$
\begin{gathered}
\mathrm{K}_{\mathrm{H}}=\frac{12 \mathrm{EI}}{\mathrm{h}^{3}\left[\alpha_{\mathrm{k}}+54 \beta_{1} \mathrm{k}^{2}+6 \beta_{2}(3 \mathrm{k}+1)^{2}\right]} \\
\alpha_{\mathrm{k}}=54 \mathrm{k}^{2}+27 \mathrm{k}+2 \\
\beta_{1}=\frac{E I_{\mathrm{c}}}{\mathrm{K}_{\mathrm{t} 2}} \frac{\mathrm{t}_{1}}{\mathrm{~h}} \\
\beta_{2}=\frac{E I_{\mathrm{c}}}{\mathrm{K}_{\mathrm{t} 1}} \frac{\mathrm{t}_{2}}{\mathrm{~h}}
\end{gathered}
$$

The influence of the elastic connections on the overall system stiffness depends on the parameter $\beta$. Through determination of the elastomeric section minimum thickness 'limt' that applies when the connection becomes rigid, the respective rotational angle $\varphi_{\mathrm{t}}$ obtains an upper value, as follows: 


$$
\max \varphi_{\mathrm{t}} \approx \frac{\lim \mathrm{t}}{\mathrm{d}}
$$

The angle $\max \varphi_{\mathrm{t}}$ divides the systems force-displacement diagram in two areas: For $\mathrm{t}<\max \varphi_{\mathrm{t}}, \beta>>\frac{2 \mathrm{k}+1}{\mathrm{k}}$, the elastic properties of the system are mainly defined by the elastic connections with controlled parameters. In this case there is an area of 'low stiffness'. If $\beta=0,(\mathrm{t} \Rightarrow 0), \varphi_{1} \Rightarrow \max \varphi_{1}$, the connection becomes rigid and the course of the characteristic line is entirely determined by the properties of the steel members. The upper limit of the second area is defined by the plastic hinges of the beam.

\section{Frame systems analysis}

The elastic connections are applied in three different bare frame systems $\left(\mathrm{S} 1,2,3_{\mathrm{b}}\right)$; a hinge supported frame $\left(\mathrm{S} 1_{\mathrm{e}}\right)$, a frame with moment resisting supports and internal hinges in the upper column zones $\left(\mathrm{S} 2_{\mathrm{e}}\right)$ and a frame with moment resisting supports $\left(\mathrm{S}_{\mathrm{e}}\right)$. In the first and second case the elastic connection are applied within the beam, in the last case within the columns lower zones (fig. 2).
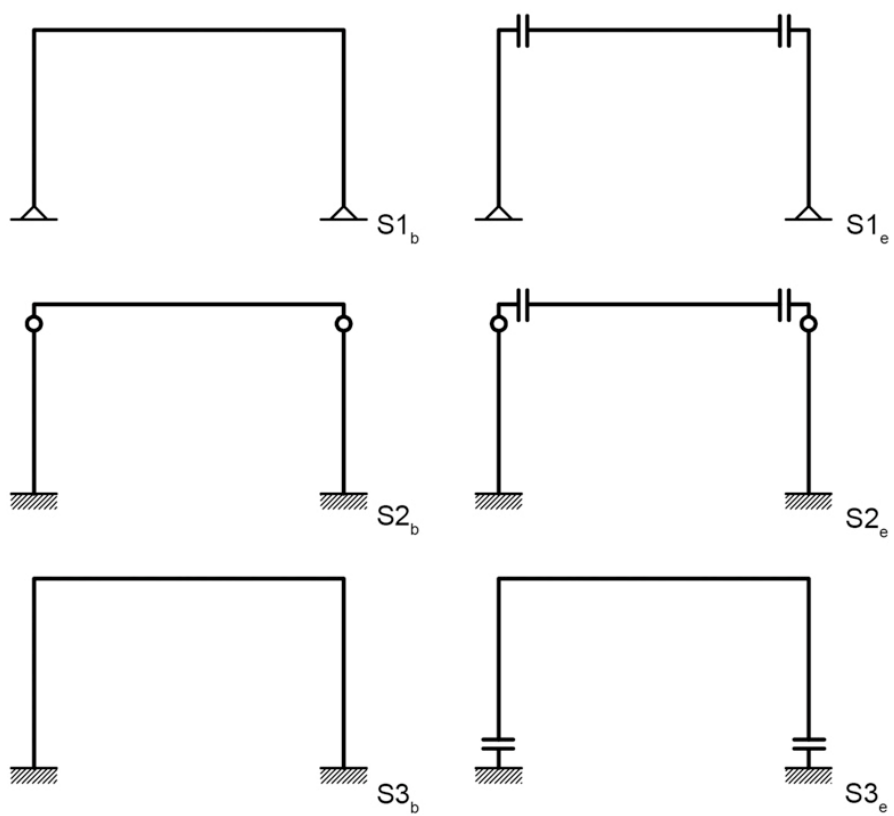

Figure 2: $\quad$ Primary frame systems and frames with elastic connections.

Each controlled system variant is compared in its dynamic behaviour to the respective primary frame reference system. The steel frames have a height of $4.00 \mathrm{~m}$, a length of $6.00 \mathrm{~m}$ and are dimensioned according to Eurocode 3 with an 
HEA220 beam section and HEA240 column sections. No damping was assigned to the systems, in order to gain deeper insight with regard to the effects on the stiffness property variations, whereas the damping effects and in extent the associated energy dissipation potential of the proposed systems are currently further studied in detail. The elastomeric layers have constant characteristics of $\mathrm{SH} 60, \mathrm{G}=0.1 \mathrm{kN} / \mathrm{cm}^{2}, \mathrm{t}=1.2 \mathrm{~cm}, \mathrm{~d}=\mathrm{b}=20 \mathrm{~cm}, \mathrm{n}=85.70$. The maximum elastomeric layer rotational angle corresponds to a compressive deformation of the elastomeric layer of up to $50 \%$ of its thickness, i.e. $\max \varphi_{t}=0.03 \mathrm{rad}$.

Finite-element analysis of the structural models is based on a simplified SDOF ideal model. Nonlinearity is addressed to the elastic connection members through a simulated nonlinear link element in the software program SAP2000. The systems behavior examined is derived from the horizontal lateral displacement, being the single free movement. The dimensioning of the members fulfilled Eurocode 3 design requirements, when subjected against the external loading. The fundamental eigen-frequencies of the systems resulted in the following values: $\mathrm{S} 1_{\mathrm{b}}$ : $\mathrm{f}_{\mathrm{s}}=0.567 \mathrm{~Hz} ; \mathrm{S} 1_{\mathrm{e}}: \mathrm{f}_{\mathrm{s}}=0.406 \mathrm{~Hz} ; \mathrm{S} 2_{\mathrm{b}}: \mathrm{f}_{\mathrm{s}}=0.815 \mathrm{~Hz}$; $\mathrm{S} 2_{\mathrm{e}}: \mathrm{f}_{\mathrm{s}}=0.812 \mathrm{~Hz} ; \mathrm{S} 3_{\mathrm{b}}: \mathrm{f}_{\mathrm{s}}=1.205 \mathrm{~Hz} ; \mathrm{S} 3_{\mathrm{e}}: \mathrm{f}_{\mathrm{s}}=1.222 \mathrm{~Hz}$. The dynamic behaviour of the systems is investigated in the time-history range for the first $30 \mathrm{~s}$ under three representative international strong earthquake motions of differing frequency contents as presented in table 1 [7].

Table 1: International earthquake input records.

\begin{tabular}{|c|l|c|c|c|c|}
\hline Case & \multicolumn{1}{|c|}{ Record } & Station & Mw & PGA [g] & Duration [s] \\
\hline A & El Centro 1940 & Imperial valley, component $180^{0}$ & 6.9 & 0.348 & 53.76 \\
\hline B & Kobe 1995 & JMA, component $0^{0}$ & 6.9 & 0.810 & 48.00 \\
\hline C & Northridge 1994 & Olive view, component $90^{0}$ & 6.7 & 0.604 & 30.00 \\
\hline
\end{tabular}

\subsection{Earthquake response behaviour}

The maximum earthquake responses of the primary and controlled frames assigned with elastic connections are presented in table 2 in absolute values.

Table 2: Frames' earthquake response behaviour.

\begin{tabular}{|c|c|c|c|c|c|c|c|c|c|}
\hline \multirow{2}{*}{ Case } & \multicolumn{3}{|c|}{$\frac{\mathrm{S} 1_{\mathrm{e}}}{\mathrm{S} 1_{\mathrm{b}}}$} & \multicolumn{3}{|c|}{$\frac{\mathrm{S} 2_{\mathrm{e}}}{\mathrm{S} 2_{\mathrm{b}}}$} & \multicolumn{3}{|c|}{$\frac{\mathrm{S} 3_{\mathrm{e}}}{\mathrm{S} 3_{\mathrm{b}}}$} \\
\hline & $\begin{array}{l}\mathrm{X}_{\max } \\
{[\mathrm{cm}]}\end{array}$ & $\begin{array}{c}\dot{\mathrm{x}}_{\max } \\
{[\mathrm{cm} / \mathrm{s}]}\end{array}$ & $\begin{array}{c}\ddot{\mathrm{x}}_{\max } \\
{\left[\mathrm{cm} / \mathrm{s}^{2}\right]}\end{array}$ & $\begin{array}{l}\mathrm{X}_{\max } \\
{[\mathrm{cm}]}\end{array}$ & $\begin{array}{c}\dot{\mathrm{X}}_{\max } \\
{[\mathrm{cm} / \mathrm{s}]}\end{array}$ & $\begin{array}{c}\ddot{\mathrm{X}}_{\max } \\
{\left[\mathrm{cm} / \mathrm{s}^{2}\right]}\end{array}$ & $\begin{array}{l}\mathrm{X}_{\max } \\
{[\mathrm{cm}]}\end{array}$ & $\begin{array}{c}\dot{\mathrm{X}}_{\max } \\
{[\mathrm{cm} / \mathrm{s}]}\end{array}$ & $\begin{array}{c}\ddot{\mathrm{x}}_{\max } \\
{\left[\mathrm{cm} / \mathrm{s}^{2}\right]}\end{array}$ \\
\hline \multirow{2}{*}{ A } & 28.01 & 38.42 & 341.50 & 29.70 & 215.00 & 1630.00 & 26.61 & 135.90 & 734.00 \\
\hline & $\overline{16.62}$ & $\overline{83.61}$ & $\overline{523.70}$ & $\overline{32.51}$ & $\overline{233.40}$ & $\overline{1734.00}$ & $\overline{11.17}$ & $\overline{115.60}$ & $\overline{1294.00}$ \\
\hline \multirow{2}{*}{ B } & 24.06 & 82.80 & 826.70 & 58.89 & 439.00 & 3344.00 & 66.98 & 342.00 & 1818.00 \\
\hline & 71.66 & 358.30 & $\overline{1877.00}$ & $\overline{58.50}$ & 436.30 & $\overline{3372.00}$ & 21.15 & 236.10 & 2467.00 \\
\hline \multirow{2}{*}{$\mathrm{C}$} & 20.69 & 77.77 & 604.10 & 40.18 & 284.60 & 2062.00 & 26.14 & 129.00 & 878.00 \\
\hline & $\overline{28.14}$ & $\overline{137.50}$ & $\overline{817.60}$ & $\overline{40.21}$ & $\overline{287.60}$ & $\overline{2072.00}$ & $\overline{13.65}$ & $\overline{145.30}$ & $\overline{1668.00}$ \\
\hline
\end{tabular}


The maximum displacement of the controlled frames remained either practically constant or increased compared to the respective response values of the primary frames, reaching up to $216.69 \%$ for the case of the fixed supported frame with elastic connections at the base of the columns, i.e. $S 3_{e}$, when the system was subjected under the strong ground movement of $\mathrm{PGA}=0.810 \mathrm{~g}$, i.e. earthquake input case B. The magnitude of the velocity response decreased slightly by the controlled frames compared to the respective response values of the primary frames, with the maximum decrease derived by $\mathrm{S} 1_{\mathrm{e}}$, resulting in $0.76 \%$ for the earthquake input case B. Similar observation is valid for the acceleration response for which the highest decrease amounted to $55.99 \%$ for the same controlled frame and when subjected under the same strong excitation, i.e. case B.

A direct comparison of the three controlled systems earthquake responses proves that the fixed supported frame with elastic connections at the base of the columns resulted in highest increase of the maximum displacement response under all dynamic excitations, followed by the hinge supported frame with elastic connections at the beams ends. The fixed supported frame with internal hinges at the columns' top and elastic connections at the beams ends followed in its earthquake responses the trend with increase of its maximum displacement and decrease of its maximum velocity and acceleration, but with lower magnitudes of the values. In particular, the earthquake displacement responses of the primary and controlled systems in the time-history range are shown in figs $3-5$.
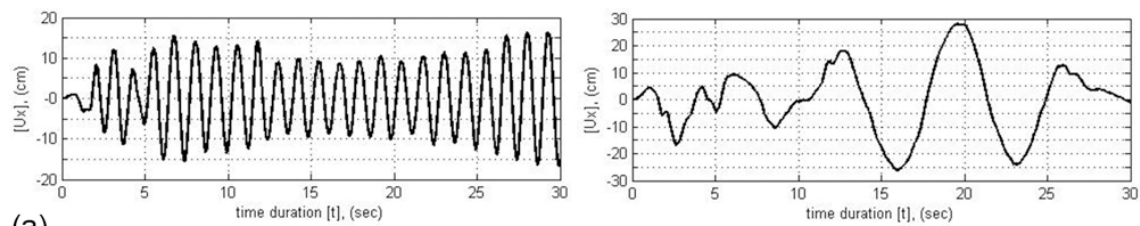

(a)
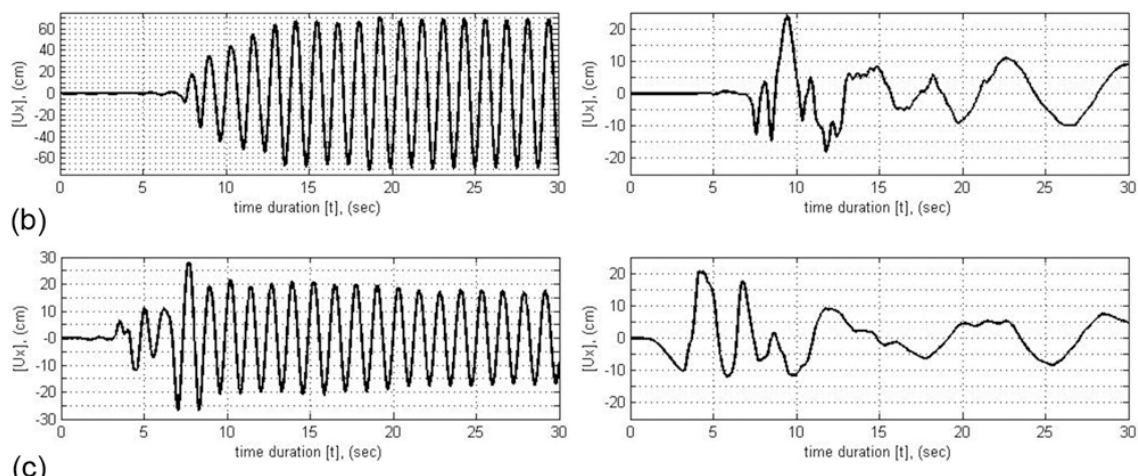

Figure 3: Time-history earthquake displacement response of hinge supported frame (left column) and the same system with elastic connections, S1e (right column): (a) Case A; (b) Case B; (c) Case C. 

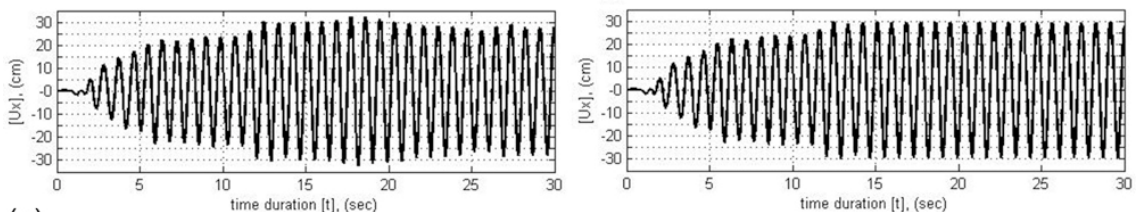

(a)
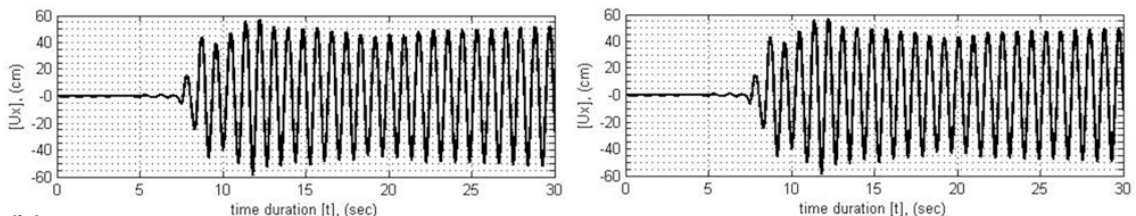

(b)
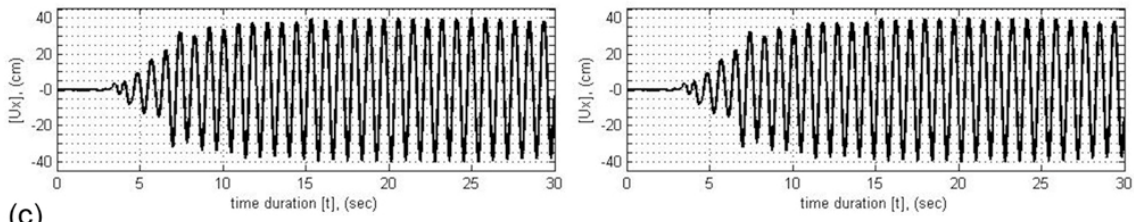

Figure 4: Time-history earthquake displacement response of frame with moment resisting supports and internal hinges in the upper column zones (left column) and the same system with elastic connections, S2e (right column): (a) Case A; (b) Case B; (c) Case C.
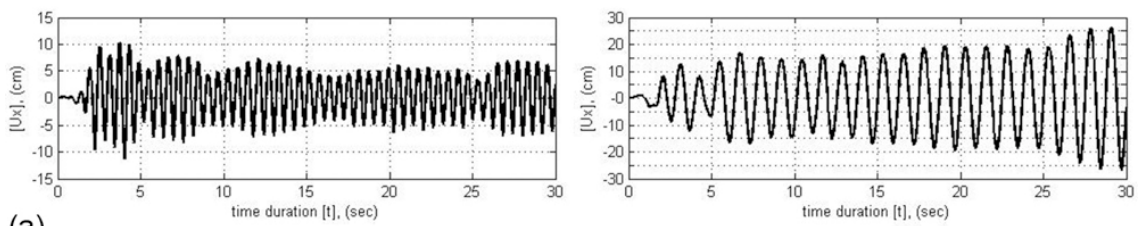

(a)
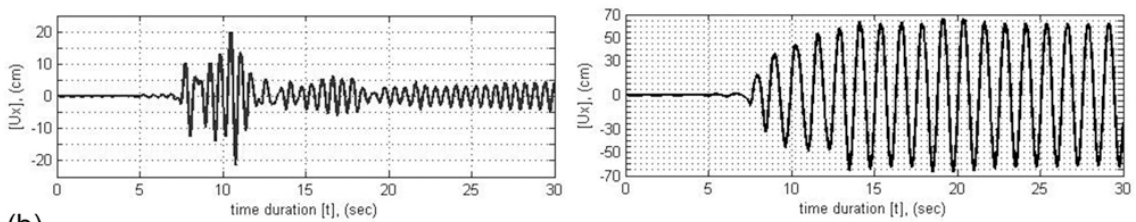

(b)
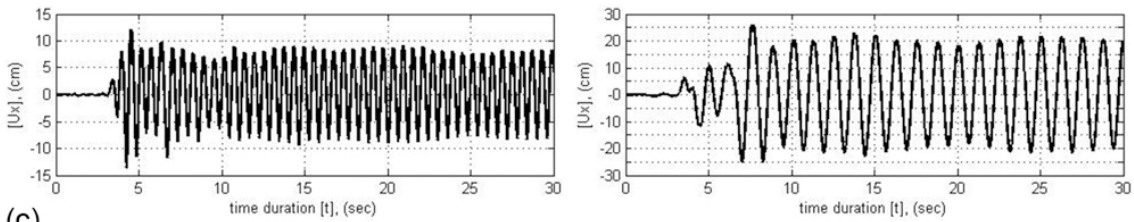

(c)

Figure 5: Time-history earthquake displacement response of frame with moment resisting supports (left column) and the same system with elastic connections, S3e (right column): (a) Case A; (b) Case B; (c) Case C. 
The systems displacement response results obtained from the dynamic analysis indicate that in general the frequency content changes when the elastic connections are involved. In particular, the length of each cycle of movement broadens, which possibly allows a better control of the inelastic cyclic deformations. The insert of the elastic connection in each system makes the displacement response function with time smoother, as also graphically represented, since the content of each graph is not as dense in $\mathrm{S}_{1 \mathrm{e}}, \mathrm{S}_{2 \mathrm{e}}$ and $\mathrm{S}_{3 \mathrm{e}}$, as it is for $S_{1 b}, S_{2 b}$ and $S_{3 b}$. The highest differentiation in this aspect may be observed in the case of the hinge supported frame with elastic connections at the beam's ends. The number of cycles of movement that the mass participates satisfactorily decreases significantly, as it is also obvious on the basis of the fundamental period of the system: $T_{\text {sle }}=2.463 \mathrm{~s}$ over $\mathrm{T}_{\mathrm{slb}}=1.764 \mathrm{~s}$, i.e. $39.65 \%$ increase. The system gains flexibility considering the variation of its lateral stiffness, while it resists against all earthquake induced ground motions that have been chosen to simulate the ground shaking.

The time that the peak displacements occur has also been evaluated in the dynamic analysis of the systems. In this respect it is observed that there was a significant delay for the maxima in the case of system $S_{3 e}$ compared to $S_{3 b}$ : the peak values were recorded at $t=29.72 \mathrm{~s}, \mathrm{t}=18.52 \mathrm{~s}$ and $\mathrm{t}=7.65 \mathrm{~s}$ for the maximum displacement, velocity and acceleration response respectively compared to the associated times of $\mathrm{t}=4.00 \mathrm{~s}, \mathrm{t}=10.76 \mathrm{~s}$ and $\mathrm{t}=4.26 \mathrm{~s}$ for the respective maximum responses of the primary frame. Such delay offers the opportunity to gain valuable time especially before the maximum displacement occurs when the elastic connections are added at the base supporting columns of moment resisting frames.

\section{Conclusions}

In the present paper elastic connections of the primary members of steel frames have been proposed that mainly consist of an elastomeric layer. The presented concept refers to a control technique of structural behaviour under earthquake actions using connections with changeable characteristics that may at first place control the stiffness of the primary system and provide the main system with adaptability features to different loading conditions. Conceptually it is assumed that the structural deformability is conditioned mainly by the elastic connections with complex functionality, alone able to control the partial and overall stiffness, the force transmission and partly, the energy dissipation process. The dynamic analysis of three different controlled frames conducted in the current paper proved an increase of the maximum response displacements and slight decrease of the velocity and acceleration values compared to the respective primary systems. For improving the energy dissipation capacity of the structure, the control concept may further comprise dynamic adaptable connections, which represent as a whole two systems; a primary rigid one, composed for example of steel wedges with low yield capacity, and a secondary kinematical one, as proposed in the current paper, which is only activated under dynamic actions, i.e. after exceeding the upper limit of the force that can be induced in the rigid 
connections of the structure. Such dynamic adaptable connections are currently further investigated by the authors.

\section{References}

[1] Paulay, T., Bachmann, H. \& Moser, K., Erdbebensicherung von Stahlbetonhochbauten. Birkhäuser: Basel, 1990.

[2] Engel, H., Structure Systems. Hatje Cantz: Stuttgart, 2009.

[3] Mahmoodi, P., Structural Dampers. Journal of the Structural Division $A S C E$, 95(8), pp. 1661-1672, 1969.

[4] Newmark, N. \& Rosenblueth, E., Fundamentals of Earthquake Engineering. Prentice-Hall Inc.: New York, 1971.

[5] Pocanschi, A. \& Phocas, M.C., Kräfte in Bewegung. Die Techniken des Erdbebensicheren Bauens. Teubner: Wiesbaden, 2003.

[6] Di Sarno, L. \& Elnashai, A.S., Innovative Strategies for Seismic Retrofitting of Steel and Composite Structures. Progress in Structural Engineering and Materials, 7, pp. 115-135, 2005.

[7] Phocas, M.C. \& Sophocleous, T., Adaptable Dual Control Systems. A Comparative Parametric Analysis. Safety and Security Engineering, 2(3), pp. 280-296, 2012.

[8] Martelli, A., Seismic Isolation and Energy Dissipation: Worldwide Application and Perspectives. Earthquake Resistant Engineering Structures VI, ed. Brebbia, C.A., WIT Press: Southampton, pp. 105-116, 2007.

[9] Pocanschi, A. \& Phocas, M.C., Steifigkeits- und Dämpfungskontrolle in Stabtragwerken unter Erdbebenbeanspruchung. Bautechnik, 78(6), pp. 412-420, 2001.

[10] Block, T., Eggert, H. \& Kauschke, W., Lager im Bauwesen. Ernst \& Sohn: Berlin, 3. ed., 2013. 